\title{
Da estatística educacional para a estatística: das práticas profissionais a um campo disciplinar acadêmico'
}

Martha Raíssa lane Santana da Silva"

Wagner Rodrigues Valente"

I- Este texto é um dos resultados parciais do projeto A matemática na formação do professor do ensino primário em tempos de escolanovismo, 1930-1960, realizado pelo GHEMAT - Grupo de Pesquisa de História da Educação Matemática (www.unifesp.br/centros/ghemat), com apoio do CNPq. Ressalte-se que utilizou dados da dissertação de mestrado de Silva (2013), uma das dissertações elaboradas no âmbito do projeto, que se debruçou sobre a presença dos saberes matemáticos na formação do pedagogo, em análise histórica realizada com documentação da FFCL-USP e FNFi-RJ. Com a documentação inventariada, posteriormente, foi possível analisar o movimento de constituição acadêmico-disciplinar da estatística, tema deste estudo.

II- Universidade Federal de São Paulo, Guarulhos, SP, Brasil.

Contatos: martharaissa@gmail.com;

wagner.valente@unifesp.br

\section{Resumo}

Este artigo analisa o movimento de transformação das práticas estatísticas colocadas a serviço da educação rumo à institucionalização da estatística como disciplina científıca, no período entre 1930 e 1960. Para tanto, consideram-se sobretudo os documentos contidos no arquivo da Faculdade de Filosofia, Letras e Ciências Humanas da Universidade de São Paulo. A análise leva em conta os estudos de Ivor Goodson relativos aos padrões e processos de consolidação de uma rubrica acadêmica. 0 resultado do estudo aponta para as ações do professor Milton Rodrigues com vistas à promoção e ao deslocamento dos saberes estatísticos como método para o trabalho nas áreas da educação, da psicologia e da sociologia, em direção à estatística como campo de pesquisa, com seus próprios métodos, objetos de investigação e referências teóricas. As ações do referido professor em favor da instituição de um espaço para a formação do estatístico constituíram-se em um deslocamento significativo e concederam status de cientificidade às diversas produções nas quais a estatística era demandada. Salienta-se que, à época, a estatística, apesar de ser um conhecimento amplamente utilizado, padecia da ausência de um importante aspecto na configuração de uma disciplina acadêmica: a existência dos cursos de formação especializados, que compõem uma comunidade disciplinar.

\section{Palavras-chave}

Estatística educacional - Estatística - Pedagogia científica - Disciplina 


\title{
From educational statistics to statistics: from professional practices to an academic disciplinary field
}

\author{
Martha Raíssa lane Santana da Silva" \\ Wagner Rodrigues Valente"
}

I- This article is one of the partial results of the Project Mathematics in the formation of the elementary school teacher at the time of New School [in Brazil], 1930-1960, conducted by the GHEMAT - Research Group on History of Mathematical Education (www.unifesp.br/centros/ghemat), with the support of the National Research Council $(C N P q)$. It must be highlighted that data from Silva's M.A. thesis (2013) was utilized, as it was one of the theses produced in the scope of the aforementioned project, which addressed the presence of mathematical knowledge in the education of pedagogues, in a historical analysis which used documents from FFCL-USP and FNFIRJ. Upon documentation inventory, it was possible to analyze the movement that instituted statistics as an academic discipline, which is the subject-matter of this study..

II- Universidade Federal de São Paulo, Guarulhos, SP, Brasil.

Contacts: martharaissa@gmail.com; wagner.valente@unifesp.br

\section{Abstract}

This article analyzes the movement of transformation of statistical practices put at the service of education towards the institutionalization of statistics as a scientific discipline, from 1930 to 1960. To do so, the analysis included mainly documents from the archives of Faculdade de Filosofia, Letras e Ciências Humanas, Universidade de São Paulo. The analysis takes into account the studies by Ivor Goodson regarding the patterns and processes that consolidate an academic heading. The findings of the study point to the actions of professor Milton Rodrigues aimed at turning statistical knowledge as a method of work in education, psychology and sociology into statistics as a research field, with its own methods, objects of investigation and theoretical framework. The actions of the aforementioned professor to establish space for the training of statisticians resulted in a significant displacement and provided several productions involving statistics with a scientific status. At the time, despite being widely utilized, statistics lacked an important aspect for the configuration of an academic discipline: specialized training courses, which make up a disciplinary community.

\section{Keywords}

Educational statistics - Statistics - Scientific pedagogy - Discipline. 


\section{Introdução}

Este texto analisa o movimento de constituição da estatística como campo disciplinar acadêmico, considerando como locus de análise a antiga Faculdade de Filosofia, Ciências e Letras, atual Faculdade de Filosofia, Letras e Ciências Humanas da Universidade de São Paulo (FFLCH). 0 recorte temporal escolhido, 1930-1960, foi período no qual se verifica uma popularização da prática da estatística em diversos campos do conhecimento. Neste artigo, considera-se especificamente o campo da educação frente ao desenvolvimento de ações, vislumbrando a constituição da estatística como um campo acadêmico, disciplinar. Os mecanismos acionados para a legitimação e constituição de um campo acadêmico são analisados no texto a partir das práticas desenvolvidas com a rubrica de estatística educacional, atributo pelo qual ganha grande visibilidade, mas da qual precisa se desprender para a constituição de um campo autônomo, sem amarras na especificidade dos temas em que se tem aplicação.

Em um primeiro momento do estudo, analisam-se os discursos e políticas de um tempo de valorização das práticas estatísticas como mecanismo de base para elaboração de ações amplas em nível nacional, rumo à constituição de um orgânico sistema de ensino. Esse tempo refere-se à tentativa de ultrapassagem do que era considerada uma etapa pré-científica das humanidades, em direção ao tratamento sistematizado e profissional dos assuntos educacionais.

Posteriormente, abordam-se, mesmo que de forma breve, as transformações ocorridas na ambiência escolar, de modo a tornar possível a instalação das práticas estatísticas. Por fim, analisam-se as ações constituintes pelo movimento de organização da disciplina acadêmica estatística, evidenciando-se a realização de práticas estatísticas que antecederam a criação do campo científıco-acadêmico.

Ao longo do texto, portanto, buscar-se-á responder a pergunta que orientou este estudo: como as práticas estatísticas deram lugar à estatística como disciplina científica?

\section{Tempos de controle: discursos e políticas de valorização das práticas estatísticas}

A organização de um sistema nacional de ensino, uma demanda apresentada desde a Primeira República, mobiliza intelectuais do país no sentido de indicar caminhos para a efetivação dessa organização. A elaboração de estatísticas escolares é um dos mecanismos postos como necessários a esse intento. Por meio dessas avaliações, seria possível identificar a situação real da oferta de ensino público e privado, reconhecidos como elementos necessários para a elevação da cultura do povo brasileiro e, por conseguinte, o desenvolvimento do país (MONARCHA, 2009).

A pesquisadora Natália Gil (2007) investigou as representações construídas acerca da escola primária do Brasil, a partir da análise de documentos publicados por instituições associadas à produção de estatísticas, como a Diretoria Geral de Estatística (DGE), o Ministério da Educação e Saúde, o Instituto Nacional de Estudos e Pesquisas (INEP) e o Instituto Brasileiro de Geografia e Estatística (IBGE). 0 objetivo da pesquisadora foi estudar a legitimação das estatísticas educacionais como fontes de informação objetiva e racional, à época, que possibilitaram também a tomada de decisões políticas acerca das questões educacionais. Gil (2007) considerou as iniciativas do poder público para a criação de instituições que fornecessem informações numéricas, confiáveis, precisando como se obtinham esses números e quais as fontes educacionais utilizadas.

A pesquisa investigou, ainda, os procedimentos para a análise das interpretações acerca dos números do ensino, identificando a existência de "lutas simbólicas" travadas em torno da sua interpretação legítima. Gil (2007) também considerou o desenvolvimento de ações confluindo para o controle e organização 
de um sistema escolar em que a estatística estava muito bem posta, visto tratar-se de um conhecimento carregado de racionalidade científica, objetivo e neutro.

Ilustre-se o contexto na leitura de uma carta do chefe do governo provisório, Getúlio Vargas, aos governadores, na qual é ressaltada a importância de se realizar uma "estatística rigorosa" para tomar conhecimento das possibilidades, deficiências e potencialidades do sistema escolar, como meio de alcançar o desenvolvimento do país:

[...] estabeleci como um dos meus principais objetivos administrativos conseguir, graças aos excepcionais poderes do governo revolucionário, a eficaz colaboração que se faz mister e por meio dela a integral execução das estatísticas educacionais brasileiras. Para esse fim, promoveu o meu governo o Convênio Estatístico de 21 de Dezembro de 1931 [...]. Assim, é porque considero o êxito do convênio um dos pontos capitais do programa revolucionário, pois que só ele permitirá desenvolvimento do programa sistemático e intensivo da educação popular [...]. (VARGAS, 1932, p. 140).

A centralidade que possuíam os problemas de escolarização no país estava relacionada à ideia de desenvolvimento socioeconômico da nação que, a esse tempo, se fundamentava na racionalidade científica e na organização de uma escola elementar, símbolos de uma nação moderna (GIL, 2007).

Com Vargas, as práticas estatísticas foram pensadas e executadas como conhecimento indispensável à educação, mapeando todos os aspectos do sistema escolar brasileiro, fossem eles de infraestrutura ou até mesmo pedagógicos (VALENTE, 2007).

No período de 1930 a 1940, houve intensa produção de estatísticas escolares, o que possibilitou, em 1939, o início da publicação da série $O$ Ensino no Brasil, pelo Serviço de Estatística de Educação e Saúde
(SEES), com os resultados alcançados a partir do Convênio Estatístico de 1931. Essa série tinha por objetivo apresentar os resultados da educação no país de forma padronizada, regular e frequente. Buscava-se dar visibilidade aos avanços alcançados e, ao mesmo tempo, demonstrar as diferenças de desempenho nos estados (GIL, 2012).

Lourenço Filho, ainda na década de 1930, publicou o livro Tendências da educação brasileira, no qual se reservou um capítulo para justificar a necessidade de uma estatística educacional, de modo a se obter uma educação organizada e objetiva no seu funcionamento, com metas claras e passíveis de serem avaliadas (LOURENÇO FILHO, 1940). Na mesma publicação, o autor mencionou o Convênio Interestadual de Estatísticas Escolares, de 1932, o mesmo anunciado pelo presidente Vargas (citado anteriormente). Quanto à importância do convênio, afirmou:

Até esse ano, a comprovação do valor da estatística, no que diga respeito ao planejamento e organização da educação, pode ser feita pela negativa. Não será exagero dizer-se que a despreocupação dos problemas de ensino primário, até essa época, como obra nacional, se deve, em grande parte, à falta de levantamentos estatísticos periódicos, que tivessem atestado 0 andamento excessivamente vagaroso do crescimento dos sistemas escolares estaduais. (LOURENÇO FILHO, 1940, p. 147).

Nessa época, Lourenço Filho defendeu a estatística como sendo um método e não uma ciência ${ }^{1}$. Ao defender de forma veemente a pertinência do método estatístico para a educação, o autor afirmou haver dois usos, como se pode ler, na sequência:

1- Posteriormente, neste texto, mostrar-se-á a postura do professor Milton Rodrigues, catedrático de estatística educacional na FFCL - USP, defendendo-a como uma ciência. 
Para o vocábulo estatística duas aplicações correntes existem: uma, a de significar a simples apresentação de registros numéricos de coisas ou de pessoas, naquilo que interessem à vida do Estado; outra, no sentido de processo lógico ou método, com que esses mesmos resultados possam ser analisados e interpretados e, já agora, não só no domínio dos fatos que interessem ao Estado, mas no de todo e qualquer conhecimento humano. (LOURENÇO FILHO, 1940, p. 126).

No sentido da utilização das práticas estatísticas como forma objetiva de associação e interpretação dos dados coletados, Lourenço Filho apresentou exemplos de como esse método, no século XIX, foi sendo incorporado à física, à biologia e à psicologia. Para o autor, o primeiro registro do uso da estatística na educação foi com o psicólogo Edward Lee Thorndike, em 1903, na Columbia University, de Nova York (LOURENÇO FILHO, 1940, p. 132).

0 uso da estatística foi proposto como forma de possibilitar à educação um discurso de autoridade científica. A saída do amadorismo, dos tempos considerados pré-científicos das humanidades, tem relação com o uso de metodologias das ciências naturais e das ciências exatas. Assim sendo, a preocupação de Lourenço Filho - ícone do novo tempo pedagógico - era garantir a organização de um sistema de ensino e dar objetividade aos processos educativos, por meio da compreensão da educação enquanto um processo racionalizado pela experimentação e milimetricamente planejado e executado com bases nos resultados estatísticos.

Aos discursos oficiais, ligados a políticas de governo em prol das práticas estatísticas, aliaram-se, por esse mesmo tempo, outros argumentos de caráter mais técnico e científico: os discursos médico-pedagógicos.

0 uso da estatística nos espaços educativos foi justificado a partir da veiculação desses discursos, que despontaram em fins do século XIX, os quais tomaram por tema o estudo da infância, essa fase da vida que, à época, estava legalmente destinada ao confinamento nos espaços escolares. Os estudos médico-pedagógicos, por sua vez, legitimavam e davam caráter de cientificidade à pedagogia que se apoiava na biologia (biometria), na psicologia (psicometria), fisiologia, antropometria, medicina, sociologia e na estatística (MONARCHA, 2009).

Esses conhecimentos encontraram a sua justa utilização a partir da ampliação da escolarização pois, com ela, o público que passou a frequentar a escola era o mais diverso possível. Não somente isso, a ampliação desse público tornava urgente a necessidade de métodos educacionais que auxiliassem a educação de grandes massas, em um mesmo ritmo de tempos e com economia de recursos (SOUZA, 2009).

A organização da escola em classes foi uma resposta para a ampliação da oferta da escolarização, propondo a homogeneidade de turmas escolares, que eram previamente selecionadas a partir da aplicação dos testes de inteligência, os quais pretendiam avaliar potencialidades e limitações dos alunos, em relação à aprendizagem. Essa homogeneização objetivava a reunião, em uma classe, de crianças com o mesmo nível intelectual, mesmo ritmo, mesma prontidão para leitura e escrita, a fim de ser possível a um único professor ministrar um mesmo ensino a todos (SOUZA, 2009).

Desse modo, a necessidade de organização do sistema de ensino, levando em conta a cientificidade com o trato das questões educacionais, constituiu argumento em favor das práticas estatísticas, práticas de uma estatística educacional.

\section{As práticas estatísticas na educação: a estatística educacional}

As práticas estatísticas como ingrediente para subsidiar os organismos oficiais na gerência da educação implicam mudanças no cotidiano das escolas. Há a necessidade de preparar dados estatísticos para que essas práticas possam ser realizadas. A leitura da realidade escolar precisa de instrumentos para ganhar objetividade 
numérico-matemática. Essa preparação dos dados tem nos relatórios das delegacias regionais de ensino $^{2}$ a sua melhor objetivação. Os relatórios

\section{[...] trazem centenas de informações} quantitativas do funcionamento das escolas inspecionadas. São dados como número de matrículas, de alunos efetivamente cursando a escola, dos realmente alfabetizados. Esses dados são distribuídos por tipos e localização das escolas, gênero, idade etc. (CELESTE FILHO, 2012, p. 104).

Se os relatórios representam a produção de um mapa da situação das escolas de uma dada região, no interior de cada uma das escolas, alguns instrumentos foram padronizados com o fim de organizar e conceder informações a serem incluídas nesses relatórios, de modo a viabilizar as operações estatísticas.

Um exemplo desses instrumentos são os livros oficiais de registro - livros de matrícula - utilizados a serviço da organização de um sistema escolar, caracterizando no período a tentativa de uma uniformização da coleta de dados educacionais para "dimensionar o 'quadro' do ensino nacional, suas carências, e, por fim, os requisitos necessários a uma mudança significativa de seu patamar de qualidade" (SANTOS, 2007, p. 34). Essa afırmação fundamenta-se no fato de que parte das informações contidas nos livros de matrícula compunham, também, as informações estatísticas da educação no país (SANTOS, 2007, p. 25).

Desse modo, as escolas foram tomadas pelo discurso em defesa da necessidade de medida e objetividade do seu trabalho. Os relatórios dos inspetores da Instrução Pública de São Paulo dedicavam numerosas páginas

2- "Pouco mais de três meses após a criação do Ministério da Educação e Saúde Pública, em março de 1931, é criada a Secretaria de Estado da Educação e Saúde Pública de São Paulo. Nesse ano e no seguinte, são organizadas as Delegacias Regionais de Ensino do Estado de São Paulo. As 21 Delegacias Regionais têm como uma das suas incumbências iniciais inventariar todo o sistema escolar paulista de então. Para tanto, de 1933 a 1944, elaboraram ao menos 68 relatórios detalhando a consolidação, durante o período varguista, do aparato de ensino no estado de São Paulo" (CELESTE FILHO, 2012, p. 73). para o que denominavam ser uma estatística comparada. Essas estatísticas apresentavam sínteses do movimento escolar com dados sobre matrículas, aprovações, reprovações, frequência e alfabetização (SÃO PAULO, 1938).

As práticas estatísticas desenvolvidas a partir da reorganização do aparato burocrático-documental de cada escola deram conteúdo à rubrica estatística educacional. Firmada como uma metodologia, como bem queria Lourenço Filho, acabou por parametrizar uma leitura do cotidiano das escolas, em termos de um modo de análise do funcionamento do sistema de ensino.

As práticas estatísticas mobilizadas pelo Estado para a gerência da educação, alcunhadas de estatística educacional, representam ações que dão cientificidade às políticas educacionais conduzidas a partir, sobretudo, da década de 1930. Assim,

Seja tomando de empréstimo categorias já consagradas nos discursos educacionais, seja cunhando e colocando em circulação um novo léxico, os textos estatísticos acabam por se configurar como uma importante retórica na produção não apenas dos diagnósticos acerca das mazelas ou dos avanços do sistema de ensino mas também como uma estratégia fundamental de sua organização e funcionamento como instituição social. (CALDEIRA-MACHAD0; BICCAS; FARIA FILHO, 2013, p. 655).

As práticas estatísticas na educação, para além de se assentarem em um saber técnico colocado a serviço da nova ordem burocráticocientificizante do Estado, possibilitaram uma nova leitura da educação, um novo modo de pensar o processo de escolarização da população. Foi justamente esse novo modo que construiu novas representações para os sujeitos escolares:

[...] a estatística empresta aos discursos educacionais uma retórica de cientificidade. É esta retórica, construída não apenas pela mobilização dos números, mas também, e 
sobretudo, pelas formas de dar visibilidade aos mesmos (tabelas, gráficos, imagens...), que autoriza e justifica a ação dos gestores sobre a realidade que, no mesmo ato, dá a ver. Nesta perspectiva, os "alunos" e os "professores”, ou seja, as características que identificam estes sujeitos escolares específicos sobre quem se fala, ou seja, sobre quem se age, resultam desse investimento. 0 que significa dizer, também, que eles são classificados de forma a autorizar a própria ação dos gestores e intelectuais sobre os mesmos. (CALDEIRA-MACHAD0; BICCAS; FARIA FILHO, 2013, p. 655).

Quanto à produção de estatísticas escolares nos anos de 1930 e 1940, Gil (2012) identificou a existência de dois discursos representativos de campos distintos no jogo estatística e educação, a respeito do qual afırma:

Alguns se empenham, primordialmente, enquanto expõem, comentam, analisam, explicam, manuseiam os dados quantitativos do ensino brasileiro - em legitimar a própria estatística, afırmando sua importância, ressaltando sua necessidade e mencionando a autoridade daqueles que a produziam e a examinavam. Outros se preocupam em ressaltar a utilidade das estatísticas na condução da política educacional do país e, efetivamente, as utilizam na construção da argumentação em defesa das medidas administrativas consideradas as mais acertadas. (GIL, 2012, p. 512).

Tal diferenciação se dá em um período de luta pela configuração do caráter científico do campo educacional, que passa a se assentar em bases objetivas vindas da experimentação e coleta de dados para a produção estatística - ao modo da psicologia experimental, que ascende ao status de ciência - e, de forma semelhante, da demanda de institucionalização da estatística como campo científico, para além das suas aplicações e práticas específıcas.

\section{Das práticas estatísticas nas escolas para a estatística na universidade}

A defesa da necessidade do acesso à educação para toda a população brasileira impulsionou a organização de um sistema escolar que possibilitasse uniformidade da oferta de ensino para toda a nação. Logo emergiram necessidades de infraestrutura, de financiamento das escolas, de manutenção física, de aquisição de material pedagógico, de remuneração de professores etc. Em meio a esses elementos considerados fundamentais, também está presente a demanda por formação de professores, conforme os ideários pedagógicos mais modernos da época (SOUZA, 2009).

Quanto às orientações para a formação de professores, Carvalho (2000) destaca a existência de dois estilos de formação que tentaram nortear a prática pedagógica nas cinco primeiras décadas do período republicano, legitimando-se como inauguradores de um saber pedagógico novo, moderno, experimental e científico, os quais disputavam a configuração do campo dos saberes pedagógicos necessários à prática pedagógica. Demonstra, entretanto, a passagem de um modelo que concebe a pedagogia como arte de ensinar, possível com base na imitação de modelos, para uma pedagogia, a partir do século XX, fundada em saberes autorizados, de base científica (CARVALHO, 2000).

Nesse mesmo cenário, a educação em larga escala era defendida como resposta a uma demanda de intensas transformações. Urgia organizar um sistema nacional de educação, laico, segundo novos princípios, refutando a pedagogia clássica, de base filosófica, para dar lugar aos conhecimentos médico-pedagógicos, sociológicos e estatísticos no trato das questões educacionais:

Dito melhor ainda, com essas aquisições valiosas no ativo da ciência consolidava-se um domínio disciplinar positivo e instrumental centrado no estudo da infância, 
para o qual convergiam disciplinas repentinamente dotadas de sentido educativo: medicina, antropometria, fisiologia, biologia, psicologia (normal e anormal), sociologia e estatística. (MONARCHA, 2009, p. 34).

0 período que antecede o início do século XX foi marcado por inúmeras produções dos "médicos educadores" a respeito da criança, sua constituição, sua educação, a partir dos enfoques "médico, biopsicológico, sociológico e estatístico” (MONARCHA, 2009, p. 34).

Tais propostas deveriam nortear a prática de professores e de profissionais que atuavam no âmbito escolar (inspetores, administradores escolares, formadores de professores etc.). Assim, discutia-se a importância de se promover formação em nível superior, a qual teve seu início nos Institutos de Educação (IE). Esclareça-se que, no caso de São Paulo, o IE foi incorporado à Universidade de São Paulo (USP), quando esta foi organizada, no ano de 1934. A USP compunha-se por várias faculdades e institutos, dentre eles os Institutos de Educação (IEs) e a Faculdade de Filosofia, Ciências e Letras. Os IEs tinham por objetivo a produção e disseminação de conhecimento no âmbito das ciências da educação (BONTEMPI JUNIOR, 2007).

A Faculdade de Filosofia, Ciências e Letras (FFCL) reunia uma série de cursos superiores, sendo uma das diversas faculdades que compunham a USP. Consta nos Anuários da FFCL - USP que o decreto 6.583, de 25 de janeiro de 1934, incorporou os cursos superiores do Instituto de Educação à FFCL, com o intuito de fornecer a formação pedagógica em nível superior dos bacharéis concluintes dos seus cursos, por meio das disciplinas: biologia educacional; psicologia educacional; sociologia educacional; história e filosofia da educação; educação comparada e metodologia do ensino secundário. Esse formato permaneceu ao longo dos anos de 1936, 1937 até o primeiro semestre de 1938, quando o decreto estadual 9268-A, de 25 de junho, extinguiu o IE e criou a secção de Educação na FFCL - USP. (USP, 1953a).
Em meio a uma série de mudanças para a formação de professores e o estabelecimento de um discurso científico para a educação, criou-se, em 1939, o curso de pedagogia. Esse curso foi criado por meio do Decreto-Lei $n^{\circ} 1.190$, que estabelecia a organização da Faculdade Nacional de Filosofia (FNFi), tornando-a padrão para as demais faculdades de filosofia, dentre elas a FFCL - USP, destinando o curso de pedagogia a essas faculdades. A FNFi integrava o conjunto de instituições da Universidade do Brasil (UB), situada na cidade do Rio de Janeiro, quando Distrito Federal (UNIVERSIDADE DO BRASIL, 1951), assim como a FFCL integrava a USP.

0 Decreto-Lei $\mathrm{n}^{\circ} \quad 1.190$ também estabeleceu o currículo das faculdades de filosofia, as quais comportavam diversos cursos, como o de pedagogia, ciências sociais, dentre outros. Apenas para esses dois cursos foi estabelecido o estudo de estatística, por meio das disciplinas estatística educacional e estatística geral e aplicada, respectivamente (BRASIL, 1939).

Em 1939, período de instituição de um currículo padrão para as faculdades de filosofia, a estatística estava, há algum tempo, sendo utilizada e defendida no meio educacional. Assim, praticava-se a estatística. $\mathrm{Na}$ sociedade, em geral, o seu uso data de antigas civilizações, não cunhada com este termo, estatística, tampouco com as especificações e possibilidades que ela apresentava nas primeiras décadas do século XX. 0 conhecimento estatístico esteve nas suas origens atrelado às atividades do Estado entretanto, o século XX marca uma outra perspectiva da estatística definida como "ciência da contagem dos constituintes da sociedade" e "ciência do cálculo em vista da análise das contagens" (MARTIN, 2001), passando a constituir significativamente a produção das ciências sociais.

No Brasil, a estatística teve um importante personagem, o médico e sanitarista Bulhões Carvalho, a quem foi atribuído o título de fundador da Estatística Geral Brasileira, pela Assembleia Geral do Conselho Nacional de Estatística, em 1938. Essa importância justifica-se pela atuação 
principalmente no Diretório Geral de Estatística (DGE), órgão recriado em 1890, que tinha como uma das atribuições a realização do censo populacional a cada dez anos (determinação constante na Constituição de 1891) e, por sua vez, a produção de estatística de alcance nacional (SENRA, 2009).

Vários foram os diretores do DGE. Entretanto, foi somente com a direção de Bulhões de Carvalho, a partir de 1907, que esse Diretório operou avanços. Segundo Senra (2009), as dificuldades para um desempenho satisfatório do DGE deviam-se à ausência de sustentação teórica, por parte dos seus diretores e técnicos envolvidos para a execução das estatísticas. Até 1920 , os censos realizados sofreram sérias críticas e não conseguiam atender às demandas solicitadas. Com a direção de Bulhões, a estatística não foi apenas executada, mas foi objeto de reflexão e discussão (SENRA, 2009).

Trabalhando à frente do DGE, Bulhões deparava-se com os problemas relativos à formação dos técnicos do diretório e à inexistência de uma carreira de estatístico, o que causava instabilidade no quadro de trabalhadores. Ciente da necessidade de formação específica para o trabalho e não havendo locus para tal, Bulhões trabalhou para a realização da tradução e edição do Manual de estatística, de Filippo Virgilii, e organizou concursos para admissão de novos técnicos, dentre eles, Mário Augusto Teixeira de Freitas, que fundou, posteriormente, o IBGE.

Bulhões tornou-se referência na área, sobretudo pelo sucesso do censo de 1920: "Nunca antes o país planejara tão minuciosamente um recenseamento" (SENRA, 2009, p. 392). 0 censo de 1930 não foi realizado, por conta do movimento revolucionário. 0 DGE foi extinto em 1931, criando-se, em 1934, o IBGE, instalado em 1936 (SENRA, 2009).

Do exposto é sabido que a prática da estatística não provinha de aplicação de uma rubrica universitária, não representava uma transposição aplicada de um campo científıco. A estatística ainda não estava sistematizada como uma disciplina acadêmica: campo de conhecimento que promove formação, legitima discursos, com métodos e questões próprias.

Em 1926, organizam-se os primeiros cursos de estatística aplicada à saúde pública; em 1932, cria-se a cadeira de estatística aplicada à educação no Instituto de Educação do Distrito Federal (Rio de Janeiro), regida pelo professor José Paranhos Fontenelle e, em 1933, a mesma cadeira é criada no IE-USP, regida pelo professor Milton C. Rodrigues (LOURENÇO, 1940). Em 1939, como já apontado, a disciplina de estatística passou a compor obrigatoriamente os currículos do curso de pedagogia e de ciências sociais (BRASIL, 1939). Tais marcos instalam o ensino de técnicas estatísticas a serem utilizadas em diferentes campos, sobretudo os da saúde, da educação, da sociologia e da psicologia.

Importa destacar que a primeira escola superior de estatística do Brasil e da América Latina foi criada apenas em 1953, no Rio de Janeiro, vinculada ao IBGE. Contudo, a profissão de estatístico só foi instituída no país em 1965, pela lei $\mathrm{n}^{\circ} 4.739$, e regulamentada em 1968, pelo decreto $\mathrm{n}^{\circ} 62.497$ (ESCOLA NACIONAL DE CIÊNCIAS ESTATÍSTICAS - ENCE).

Entretanto, antes da criação dessa escola superior, o professor de estatística II (antiga estatística educacional), da Faculdade de Filosofia, Ciências e Letras da USP, e chefe do Departamento de Estatística dessa instituição, Milton da Silva Rodrigues, presidiu uma comissão para a criação de um instituto de estatística, em 1949 (UNIVERSIDADE DE SÃO PAUL0, 1949).

É válido salientar que a proposta de criação desse Instituto reunia interesses de professores de estatística não só da Faculdade de Filosofia, como também da Faculdade de Ciências Econômicas e Administrativas e da Faculdade de Higiene e Saúde Pública, da USP e, mais tarde, de muitas outras instituições. A proposta visava a possibilitar o desenvolvimento de pesquisas em estatística, a partir das suas abordagens pura ou aplicada, formando estatísticos em diversos níveis e especialidades, concedendo certificados de 
habilitação ou universitário (UNIVERSIDADE DE SÃo PAULO, 1949).

Para o provimento das cadeiras do Instituto de Estatística não se exigiu a formação de estatístico, visto que não havia uma formação no país que superasse o formato de habilitação. 0 provimento das cadeiras para o novo instituto seria primeiramente suprido pelos professores que já lecionavam essa disciplina nos diversos cursos da USP. Posteriormente, os critérios seriam de aprovação em concurso de provas e títulos e critério de experiência docente em alguma das cadeiras de estatística, podendo concorrer todo que possuísse título universitário (UNIVERSIDADE DE SÃO PAULO, 1949).

Foi descartada a possibilidade do provimento de professores formados em estatística vindos do exterior, como era uma prática da instituição, que sempre recorria a professores de fora para conceder autoridade e garantir a qualidade dos estudos ofertados nas disciplinas. A primeira opção para a ocupação dessas cadeiras considerou professores que já lecionavam estatística em diversos cursos da própria universidade, ou seja, estava se levando em conta uma prática que antecedia a formação desses professores, e que, portanto, não previa a seleção de outros profissionais.

Nos trâmites para a criação do Instituto de Estatística, foram feitas algumas alterações no projeto e, em dois de fevereiro de 1950, foi entregue um novo anteprojeto de estatuto com maior detalhamento de algumas informações, dentre elas a formação ofertada pela instituição, que poderia ser normal, de aperfeiçoamento, especialização, livre ou de extensão universitária (UNIVERSIDADE DE SÃO PAULO, 1949).

A Assessoria Técnica Legislativa do Estado de São Paulo emitiu um ofício em 1951, ao reitor da USP, mencionando o recebimento da proposta de criação do Instituto de Estatística daquela Universidade, e pedindo que o mesmo se manifestasse a respeito da criação dessa instituição frente ao recente reestabelecimento do Departamento de Estatística, pela lei 877 de 4/12/1950, como se esse contemplasse as demandas daquele. 0 departamento mencionado era uma espécie de locus de produção das estatísticas do estado de São Paulo, filiado à União (UNIVERSIDADE DE SÃO PAULO, 1949). 0 reitor, por sua vez, pediu que 0 professor Milton Rodrigues, presidente da Comissão, respondesse às interpelações da assessoria técnico-legislativa. 0 professor assim o fez, estabelecendo a diferença entre o Departamento e o Instituto de Estatística. Esclareceu que o primeiro produz uma estatística ligada à administração pública, com um trabalho constante de levantamento de informações, enquanto o segundo objetiva a formação do estatístico, tratando-se de um órgão de pesquisa, docência e consulta. Diante disso, considerou a importância do trabalho dessas duas instituições conjuntamente (UNIVERSIDADE DE SÃO PAULO, 1949). Essa distinção, de fato, revelava a nítida diferença estabelecida para as práticas estatísticas feitas até então, e as intenções de criar uma disciplina acadêmico-científica.

A proposta de criação do instituto ficou suspensa em função de questões de financiamento necessário, de estrutura, de descentralização das faculdades da USP. 0 problema da descentralização demandava a locomoção dos professores que comporiam as cadeiras no instituto, pois ainda não havia uma cidade universitária, da USP, de forma que as faculdades estavam situadas em diferentes locais e os professores lecionariam nas suas faculdades e no Instituto de Estatística simultaneamente (UNIVERSIDADE DE SÃO PAULO, 1949).

Passados dez anos desde a primeira proposta, em 1959, o projeto de criação do Instituto de Estatística voltou a ser discutido em um parecer assinado pelo relator Luiz Antônio da Gama e Silva. No documento, sugere-se um reexame da primeira proposta, em função das transformações ocorridas ao longo de uma década, com a seguinte afırmação:

E sobre essa matéria, ninguém melhor poderá opinar, do que a Colenda Congregação 
da Faculdade de Filosofia, Ciências e Letras, da qual o proponente - Prof. Milton da Silva Rodrigues é ilustre catedrático. (UNIVERSIDADE DE SÃO PAULO, 1949).

0 professor Milton Rodrigues presidiu a primeira comissão para a criação do Instituto, o que não deve ter sido por acaso. Esse docente, formado em engenharia civil, tornou-se docente da USP quando da incorporação do antigo IE, em 1934, à FFCL - USP. Professor daquele Instituto, ministrava a disciplina de estatística e educação comparada. No processo de incorporação, o IE transformou-se na seção de educação, e, em 1939, no curso de pedagogia da FFCL - USP. Essa transformação exigiu o desmembramento da disciplina lecionada pelo professor Milton, o qual optou por lecionar apenas estatística educacional (UNIVERSIDADE DE SÃO PAULO, 1953b).

Apesar de sua formação em engenharia civil, o professor Milton Rodrigues estava originalmente vinculado à seção ${ }^{3}$ de pedagogia, no âmbito da FFCL - USP. Entretanto, ao longo da sua atuação como docente da disciplina estatística para o curso de pedagogia na FFCL - USP, demonstrou a sua filiação pelo que poderíamos considerar como campo estatístico - ainda que esse não estivesse, à época, estabelecido como campo - e não pela pedagogia ou campo da educação.

Por variados motivos, não cabíveis na presente discussão, o curso de pedagogia não era visto com bons olhos na FFCL - USP, sendo que os estudos desenvolvidos em suas cadeiras não possuíam o status dos demais da instituição (BONTEMPI JUNIOR, 2007). Nesse cenário, Milton Rodrigues defendeu a alteração da denominação da sua disciplina, estatística educacional, para estatística II; ao mesmo tempo em que sugeriu a alteração da denominação da disciplina de estatística do

3- 0 decreto lei 1.190/1939 organizou as faculdades de filosofia com secções, que comportavam diversos cursos no seu interior: Secção de Filosofia, Secção de Ciências, Secção de Letras, Secção de Pedagogia - contendo apenas o curso de pedagogia - Secção Especial de Didática (BRASIL, 1939). curso de ciências sociais: de estatística geral e aplicada (disciplina que não possuía um professor catedrático, apenas contratado) para estatística I. (SILVA; VALENTE, 2013).

Passemos, neste momento, a algumas considerações a respeito de uma importante publicação desse professor que nos concede significados para as suas ações em relação às disciplinas estatísticas.

0 professor Milton Rodrigues defendeu, em seu livro Elementos de estatística geral (1956), a unidade da ciência estatística (ele defendia a estatística como ciência e não como método) contra a ideia de existirem diferentes estatísticas. Segundo Rodrigues, cabia pensar na existência de apenas uma estatística com possibilidades de aplicação nas diversas áreas de conhecimento. Tal afırmação é digna de atenção, visto que esse professor era responsável por uma disciplina que levava o nome de estatística educacional, apesar de defender a unidade da estatística. E, como já demonstrado, o professor solicitou, da disciplina que lecionava, a retirada da alcunha educacional. A referida publicação foi considerada pelo professor de estatística da Faculdade Nacional de Filosofia ${ }^{4}$ como um dos compêndios de grande circulação (KINGSTON, 1942).

Importa-nos destacar o artigo do diretor do Departamento Estadual de Estatística de Pernambuco, publicado em 1945, na Revista Brasileira de Estatística, periódico considerado como um dos marcos pelo movimento de estruturação do campo estatístico (GIL, 2012), no qual afirma que:

[...] Até o ano de 1860, ao que sabemos, o único livro com ensinamento de estatística, no Brasil, ainda que em simples definições, foi o de Sebastião Ferreira Soares, Elementos de Estatística. (PIMENTEL, 1945, p. 6).

Em seguida, afirma haver um intervalo de vinte anos sem produção, no contexto

4 - A Faculdade Nacional de Filosofia, Rio de Janeiro, então DF, foi estabelecida como padrão federal para as demais faculdades de filosofia do país, pelo mesmo decreto que cria o curso de pedagogia, n. 1.190/1939. 
brasileiro, e aponta a publicação de Parreiras Horta (1926) e o trabalho de Bulhões Carvalho (1933), Estatística - método e aplicação, interrompendo esse intervalo. Entretanto, classifica essas publicações como atrasadas em relação à produção internacional da estatística.

Apresentando um contexto histórico para a estatística no Brasil, no qual o autor cita diversas produções, e períodos importantes, assegura então que:

[...] Até o século XX, os nossos estatistas foram, apenas, os organizadores de recenseamento e planejadores dos serviços oficiais de estatística. Isto significa que somente um dos ramos anteriormente citado - o prático ou dos cômputos penetrou no Brasil. (PIMENTEL, 1945, p. 8).

Pimentel então faz as seguintes observações quanto à publicação Lições de estatística matemática, do professor Jorge Kafuri, de 1934: "escrita de maneira elegante e com o mais rigoroso método de exposição [...]" (PIMENTEL, 1945, p. 9) o livro desse professor foi posto como a primeira obra brasileira de estatística didática. Em seguida, menciona a obra do professor Milton da Silva Rodrigues, de 1934, Elementos gerais de estatística. Quanto a ela, afirma:

Completa para o seu feitio, essa obra, escrita no complicado estilo "pour comprendre", preencheu, mesmo assim, uma grande lacuna em nosso meio cultural, oferecendo aos iniciantes em estatística, sem livros fáceis, sem escola, sem orientação, meios de travarem conhecimentos mais precisos com o método estatístico, seu espírito, suas regras, suas fórmulas mais úteis. (PIMENTEL, 1945, p. 9).

Cita também o livro do professor Fontenelle, Método estatístico na biologia e educação, "obra que prestou tão bons serviços quanto a anteriormente referida" (a obra do professor Milton) (PIMENTEL, 1945, p. 9). Conclui afirmando que:

Pode-se dizer que Bulhões Carvalho fechou o ciclo da estatística didática, no Brasil, iniciado de certa maneira por Sebastião Ferreira Soares, e que os três autores acima citados lançaram o marco de um novo ciclo, que foi o da estatística atualizada, vencendo, a bem dizer, o ponto-morto da linha de ascensão da nossa cultura nesse setor de conhecimentos. E tanto isto é verdade que os seus continuadores não tardaram e novos livros e novos trabalhos, depois de 1934, foram aparecendo. (PIMENTEL, 1945, p. 9).

Reconhecemos na figura do professor Milton Rodrigues uma luta pelo estabelecimento da estatística como um campo legitimado, com metodologia própria e, mais enfaticamente, como uma ciência. Diante do exposto, vale retomar as suas afırmações, quando defendeu a alteração da nomenclatura das disciplinas estatística geral e aplicada e estatística educacional, para estatística I e II, ofertada aos cursos de ciências sociais e pedagogia, respectivamente. Segundo ele, a conveniência de tais alterações justificava-se na futura organização de cursos de estatística. Essa "futura organização de cursos de estatística" foi apresentada dois anos depois, na forma do projeto de criação do Instituto de Estatística, anteriormente citado (UNIVERSIDADE DE SÃO PAULO, 1941-1948, fl. 192).

\section{A estatística... tornando-se uma} disciplina acadêmica

Os aspectos apresentados levam em conta, primeiramente, um período frutífero para o uso do conhecimento estatístico legitimando os discursos e as práticas na educação. Proclamou-se uma racionalização dos processos educativos, por meio do uso dos testes e das medidas em educação, como resposta a uma forma escolar configurada a partir da tentativa 
bem-sucedida ${ }^{5}$ de ampliação da escolarização, fundada na homogeneização dos corpos, dos tempos, das aprendizagens, do que aprender no micro de uma sala de aula.

0 curso de pedagogia, nesse contexto, é tomado como lOcus, ícone e monumento dos anseios pela legitimação de um discurso científico em educação, a partir da elaboração de um currículo marcado pela inclusão de disciplinas ligadas à produção dos testes, das medidas, tais como a biologia, a psicologia, a sociologia e a estatística.

Nessa perspectiva, ao analisar a disciplina estatística educacional no curso de pedagogia da FFCL - USP, em particular ${ }^{6}$, encontramos indícios de um movimento de emergência da estatística como disciplina acadêmica. Essas análises fundamentam-se em estudos do historiador inglês das disciplinas escolares, Ivor Goodson, o qual se dedicou a investigar padrões que fornecessem explicações a respeito do percurso e características de um conhecimento até a sua consagração como disciplina acadêmica.

Alguns dos padrões ressaltados por Goodson, que caracterizaram uma disciplina acadêmica, foram relacionados com as ações do professor Milton Rodrigues, no âmbito da FFCL USP. Começamos por aludir à ênfase de Goodson ao papel fundamental do professor na elevação do status de uma matéria, de um conhecimento:

A implicação do tratamento preferencial das matérias acadêmicas para o auto interesse material dos professores são

\footnotetext{
5- Bem-sucedida, pois foi uma solução encontrada para solucionar 0 problema de ensinar a todos os mesmos conteúdos, ao mesmo tempo, sem discutir 0 efeito e o que de fato representa o todos da escola, que exclui aqueles que não se encaixam na lógica classificatória dos testes.

6- Identificamos essa especificidade apenas no curso de pedagogia da FFCL - USP. Realizamos uma investigação nas únicas faculdades de filosofia públicas, em 1939, e não pudemos observar esse movimento pela estatística na Faculdade Nacional de Filosofia (FNFi) - Rio de Janeiro, visto que, dentre outros elementos destacados em Silva (2013), na FNFi não havia um departamento de estatística. Pelo contrário, observamos um movimento no qual o professor da disciplina estatística educacional, Faria Góes, sugere a supressão desses estudos, pois, segundo ele, já estavam contemplados nas disciplinas biologia educacional (disciplina lecionada por ele também) e psicologia educacional (SILVA, 2013).
}

claras: melhores proporções professor/ aluno; salários mais altos; mais dinheiro de impostos; postos mais graduados; melhores perspectivas de carreira [...] o conflito com respeito ao status do conhecimento examinável é, acima de tudo, uma batalha em torno dos recursos materiais e das perspectivas de carreira de cada professor da matéria ou da comunidade da matéria. (GOODSON, 1990, p. 251).

Diante das conclusões de Goodson a respeito do papel determinante do professor na projeção da sua disciplina, é válido destacar aspectos que denotam o envolvimento do professor da disciplina em questão, professor Milton Rodrigues. Ele foi: membro do Instituto Internacional de Estatística; convidado pela comissão do $27^{\circ}$ Congresso Mundial de Estatística para participar do evento, representando a FFCL - USP; também foi convidado pelo governo francês para estar dois meses nesse país, a fim de estabelecer relações mais estreitas entre Brasil e França no campo da estatística (UNIVERSIDADE DE SÃO PAULO, 1952, p. 278); consultor técnico em estatística metodológica do Conselho Nacional de Estatística desde 1937; membro da comissão de Ensino de Estatística do Instituto Inter Americano de Estatística, desde 1947 (UNIVERSIDADE DE SÃO PAULO, 1953b, p. 547).

Ademais, a criação de departamentos no cenário universitário é também um padrão identificado por Goodson (1990) como processo de busca da legitimação de uma disciplina. A exemplo, citamos a referência que o autor faz quanto à evolução do conhecimento geográfico, afirmando que:

0 problema central, portanto, continuava sendo o estabelecimento de departamentos nas universidades onde "geógrafos podiam ser formados" e as mudanças graduais na busca da relevância e utilidade para o aluno podiam ser controladas e dirigidas. (GODSON, 1990, p. 240). 
Os departamentos são analisados também como meios de controle e como sendo as vias que possibilitam a organização de propostas formativas da disciplina em ascensão, no interior das instituições universitárias.

É válido ressaltar que, no período sobre o qual obtivemos fontes (1939 - 1961), a partir de 1950, o professor Milton Rodrigues é sempre mencionado como diretor do Departamento de Estatística ${ }^{7}$; antes disso, não localizamos nenhuma discriminação sobre quem seria o diretor desse departamento. É oportuno enfatizar que a cadeira do professor Milton Rodrigues tinha por nome estatística II, ou seja, havia uma ordem de status entre as cadeiras de estatística da instituição (estatística I e estatística II, ou primeira e segunda cadeira de estatística), determinadas por aspectos que não sabemos ao certo, mas que conjecturamos estarem ligados à sua especificidade, quando denominada de estatística educacional, enquanto que a cadeira estatística I, anteriormente denominada estatística geral e aplicada, talvez pretendesse contemplar estudos menos específicos, ainda que ofertada a um único curso, ciências sociais.

Vale ressaltar, entretanto, a intima vinculação que Martin (2001) sinaliza entre a estatística e as ciências sociais, quando aquele conhecimento dava crédito às produções no campo das ciências humanas e sociais durante os séculos XIX e XX, afirmando que a "estatística estava associada a construção da sociologia” (MARTIN, 2001, p. 31). A educação, porém, entra nessa marcha, inicialmente pela psicologia e biologia, que eram configuradas pelas avaliações estatísticas.

0 Departamento de Estatística, sob a direção da cadeira estatística II, na pessoa do professor Milton Rodrigues, desenvolveu cursos de especialização em estatística desde 1946, cursos de férias para o Departamento de Educação Estadual, diversas atividades de cooperação com instituições externas à faculdade. A biblioteca do departamento, alvo

7- Departamento pertencente não ao curso de pedagogia, mas à FFCL - USP. de doações de títulos pelo professor Milton Rodrigues, era de responsabilidade da cadeira II, mas pertencia às duas cadeiras (UNIVERSIDADE DE SÃO PAULO, 1953b).

É importante considerar a presença intelectual de Milton Rodrigues com publicações de artigos no mais importante periódico de estatística do Brasil, a Revista Brasileira de Estatística, desde a sua primeira edição, em 1940, criada em tempos de estruturação do campo estatístico, de propriedade do IBGE (GIL, 2012).

\section{Considerações finais}

Como as práticas estatísticas deram lugar à estatística? Essa foi a questão que norteou este estudo. Para respondê-la, percorreu-se um tempo de uso das práticas estatísticas como uma das formas de tratar as questões educacionais de modo cientifico - termo bem ao gosto de uma época de assentamento do que ficou conhecido como pedagogia cientifica: uma pedagogia que se afirmou no aparato médico-bio-psicológico de avaliação estatística.

A afırmação desse tempo pedagógico levou a uma reorganização das escolas, sobretudo na preparação delas para coleta de dados para as operações estatísticas. Essa preparação envolveu um nível macro de produção de relatórios pelos administradores da educação, referenciados por instrumentos que provinham do nível micro da sala de aula de cada professor. Essa foi uma época da realização das práticas estatísticas que deram conteúdo, como se viu, a rubricas como a de estatística educacional. Tratava-se, de fato, de um conhecimento prático-utilitário, referenciado pelo meio a ser aplicado, pelo método de coletar e analisar dados, como queria Lourenço Filho.

Por outro lado, viu-se um deslocamento não apenas da natureza prática como também da desvinculação de uma rubrica específica, a educacional, para a estruturação de uma disciplina de caráter científico, com suas próprias regras, métodos e possibilidades de generalização. Esse deslocamento evidenciou 
sinais dos padrões de evolução de uma disciplina, reforçando a possibilidade do percurso de um campo originário do nível prático para a sistematização em uma disciplina acadêmico-científica.

Sob a condução do professor Milton Rodrigues, por entre as lides e meandros universitários, assistiu-se a condução das práticas estatísticas como conhecimento técnico para a estatística, campo de produção de conhecimento, desgarrado de todo e qualquer adjunto. Cabia pensar, assim, a existência de apenas uma estatística.

As ações do professor Milton Rodrigues, pela instituição de um espaço para a formação do estatístico, constituíram um deslocamento significativo, como parte de um cenário no qual a estatística, apesar de um conhecimento amplamente utilizado, que concedia status de cientificidade às diversas produções nas quais era demandada, padecia da ausência de um importante aspecto na configuração de uma disciplina acadêmica: a existência dos cursos de formação especializados, que compõem uma comunidade disciplinar.

Personagem ativo na ambiência da estatística brasileira, atuou dentro da área como chefe de departamento, consultor técnico em organização de circunscrição nacional e vinculado a instituições internacionais, dentre outras. 0 professor Milton Rodrigues encabeçou a batalha pela organização de um Instituto de Estatística no espaço de uma importante instituição, a saber, a Universidade de São Paulo, ao mesmo tempo em que articulou e coordenou os trabalhos com professores de áreas e departamentos distintos da Universidade, separados não apenas pelos campos de conhecimento que representavam, como também pelo espaço físico que se impôs como um dos fatores impeditivos da consecução da proposta.

\section{Referências}

BONTEMPI JUNIOR, Bruno. A incorporação do Instituto de Educação pela FFCL - USP: hipóteses para entender um campo cindido. In: ASSOCIAÇÃO NACIONAL DE PÓS-GRADUAÇÃO E PESQUISA EM EDUCAÇ̃̃O. Anais... GT História da educação, n. 2, CNPQ, 2007. Disponível em: <http://www.anped.org.br/app/webroot/reunioes/30ra/trabalhos/GT02-2872--Int.pdf>. Acesso em: abr. 2012.

BRASIL. Decreto-Lei no 1.190 de 04/04/1939. Organiza a Faculdade Nacional de Filosofia. Diário Oficial da União. Legislação Informatizada, 1939. Disponível em: <http://www2.camara.leg.br/legin/fed/declei/1930-1939/decreto-lei-1190-4-abril-1939349241-publicacaooriginal-1-pe.html>. Acesso em: 01 set. 2014.

CALDEIRA-MACHADO, Sandra M.; BICCAS, Maurilane S.; FARIA FILHO, Luciano M. Estatísticas educacionais e processo de escolarização no Brasil: implicações. Cadernos de História da Educação, Uberlândia, v. 12, n. 2, p. 639-658, jul./dez. 2013.

CARVALHO, Marta Maria Chagas de. Modernidade pedagógica e modelos de formação docente. São Paulo em Perspectiva, São Paulo, v. 14, n. 1, p. 111-120, jan./mar. 2000. Disponível em: <http://www.scielo.br/scielo.php?pid=S010288392000000100013\&script=sci_abstract>. Acesso em: 13 mai. 2014.

CELESTE FILHO, Macioniro. Os relatórios das delegacias regionais de ensino do Estado de São Paulo como fonte de pesquisa para a história da educação - décadas de 1930 e 1940. Revista Brasileira de História da Educação, Campinas, v. 12, n. 1 (28), p. 71-111, jan./abr. 2012.

ESCOLA NACIONAL DE CIÊNCIAS ESTATISTICAS. Disponível em: <http://www.ence.ibge.gov.br/web/ence/apresentacao>. Acesso em: jan. 2013.

GIL, Natália de Lacerda. A dimensão da educação nacional: um estudo sócio-histórico sobre as estatísticas oficiais da escola brasileira. 2007. 399 p. Tese (Doutorado em Educação) - Faculdade de Educação da Universidade de São Paulo, São Paulo, 2007. 
GIL, Natália de Lacerda. Campo educacional e campo estatístico: diferentes apropriações dos números do ensino. Educação e Realidade, Porto Alegre, v. 37, n 2, p. 511-526, maio/ago. 2012. Disponível em: <http://seer.ufrgs.br/educacaoerealidade/article/ view/16556>. Acesso em: 13 jun. 2014.

GOODSON, Ivor F. 0 currículo em mudança: estudos na construção social do currículo. Porto: Porto Editora, 2001.

GOODSON, Ivor F. Tonando-se uma matéria acadêmica: padrões de explicação e evolução. Teoria \& Educação, Porto Alegre, n. 2, p. 230-254, 1990.

KINGSTON, Jorge. Observações sobre o cálculo das separatrizes. Revista Brasileira de Estatística, Rio de Janeiro, v. 3, n. 10, abr./jun. 1942. Disponível em: <http://biblioteca.ibge.gov.br/visualizacao/monografias/GEBIS\%20-\%20RJ/RBE/RBE\%20 1942\%20v03\%20n10.pdf>. Acesso em: fev. 2013.

LOURENÇO FILHO, Manoel Bergstrom. Tendências da educação brasileira. São Paulo: Melhoramentos, 1940.

MARTIN, Oliver. Da estatística política à sociologia estatística. Desenvolvimento e transformações da análise estatística da sociedade (séculos XVII-XIX). Revista Brasileira de História, v. 21, n. 41, p. 13-34, 2001. Disponível em: <http://www.redalyc. org/articulo.oa?id=26304102> . Acesso em: 22 jun. 2014.

MONARCHA, Carlos. Brasil arcaico, escola nova: ciência, técnica \& utopia nos anos 1920- 1930. São Paulo: Edunesp, 2009.

PIMENTEL, Paulo. A estatística didática no Brasil. Revista Brasileira de Estatística, Rio de Janeiro, v. 6, n. 21, p. 5-10, jan./ mar, 1945. Disponível em: <http://biblioteca.ibge.gov.br/visualizacao/periodicos/111/rbe_1945_v6_n21.pdf>. Acesso em: 07 jun. 2014.

REVISTA BRASILEIRA DE ESTATÍSTICA, Rio de Janeiro, v. 1, n. 1, jan./mar. 1940. Disponível em: <http://biblioteca.ibge.gov.br/ visualizacao/periodicos/111/rbe_1940_v1_n1.pdf>. Acesso em: 07 jun. 2014.

RODRIGUES, Milton da Silva. Elementos de estatística geral. 5. ed. São Paulo: Companhia Editora Nacional, 1956.

SANTOS, Adriano M. 0 Arquivo da Escola Normal "Carlos Gomes": perfis e trajetórias dos alunos durante o Estado Novo. 2007. Dissertação (Mestrado em Educação) - Universidade Estadual de Campinas, Campinas, 2007.

SENRA, Nelson de C. Na Primeira República, Bulhões Carvalho legaliza a atividade estatística e a põe na ordem do Estado. Boletim do Museu Paraense Emílio Goeldi: Ciências Humanas, Belém, v. 4, n. 3, p. 387-399, set./dez. 2009.

SILVA, Martha Raíssa lane Santana da. A matemática na pedagogia da FFCL-USP e FNFi, 1939-1961. 2013. Dissertação (Mestrado em Ciências) - Universidade Federal de São Paulo, Guarulhos, 2013. Disponível em: <https://repositorio.ufsc.br/ handle/123456789/105094>. Acesso em: 03 out. 2013.

SILVA, Martha Raíssa lane Santana da; VALENTE, Wagner Rogrigues. Estatística educacional na Faculdade de Filosofia, Ciências e Letras da Universidade de São Paulo: processos de consolidação de uma disciplina. In: CONGRESSO BRASILEIRO DE HISTÓRIA DA EDUCAÇÃO, 7., Cuiabá, Universidade Federal de Mato Grosso, de 20 a 23 de maio de 2013. Anais... Cuiabá: UFMT, 2013. Disponível em: $\quad<$ http://sbhe.org.br/novo/congressos/cbhe7/pdf/06-\%20HISTORIA\%20DAS\%20CULTURAS\%20E\%20DISCIPLINAS\%20 ESCOLARES/ESTATISTICA\%20EDUCACIONAL\%20NA\%20FACULDADE\%20DE\%20FILOSOFIA.pdf>. Acesso em: 14 nov. 2013.

SOUZA, Rosa Fátima. Alicerces da pátria: história da escola primária no Estado de São Paulo (1890-1976). Campinas: Mercado de Letras, 2009.

UNIVERSIDADE DE SÃO PAULO. Ante-projeto de estatutos do instituto de estatística da USP. Arquivo da Faculdade de Filosofia, Letras e Ciências Humanas da USP. São Paulo: FFLCH, 1949.

UNIVERSIDADE DE SÃO PAULO. Atas da congregação da Faculdade de Filosofia, Ciências e Letras da Universidade de São Paulo (1941-1948). Livro I - Arquivo da Faculdade de Filosofia, Letras e Ciências Humanas da USP. São Paulo: FFLCH, 1949.

UNIVERSIDADE DE SÃO PAULO. Faculdade de Filosofia Letras e Ciências Humanas. Anuário da Faculdade de Filosofia, Ciências e Letras, 1951. São Paulo: FFLCH, 1952. 
UNIVERSIDADE DE SÃO PAULO. Faculdade de Filosofia Letras e Ciências Humanas. Anuário da Faculdade de Filosofia, Ciências e Letras, 1939-1949. v. 1. São Paulo: FFLCH, 1953a.

UNIVERSIDADE DE SÃO PAULO. Faculdade de Filosofia Letras e Ciências Humanas. Anuário da Faculdade de Filosofia Ciências e Letras, 1939-1949. v. 2. São Paulo: FFLCH, 1953b.

UNIVERSIDADE DO BRASIL. Decenário da Faculdade Nacional de Filosofia. Brasília, DF: UFRJ/FE: Proedes, 1951.

VALENTE, Wagner Rodrigues. No tempo em que normalistas precisavam saber estatística. Revista Brasileira de História da Matemática, Especial, n. 1 - Festschrift Ubiratan D’Ambrosio. dez. 2007. Disponível em: <http://www.rbhm.org.br/issues/ RBHM\%20-\%20Festschrift/29\%20-\%20Valente\%20-\%20final.pdf>. Acesso em: jan. de 2013.

VARGAS, Getúlio. Estatísticas sobre educação. Educação: Órgão da Diretoria Geral do Ensino de São Paulo, v. 12, n. 12, p. 140$141,1932$.

Recebido em: 05.04.2014.

Aprovado em: 25.06.2014.

Martha Raíssa lane Santana da Silva é doutoranda do Programa de Pós-Graduação em Educação e Saúde na Infância e na Adolescência da Universidade Federal do Estado de São Paulo (UNIFESP - campus Guarulhos).

Wagner Rodrigues Valente é professor adjunto livre-docente do Departamento de Educação da Escola de Filosofia, Letras e Ciências Humanas da da Universidade Federal do Estado de São Paulo (UNIFESP - campus Guarulhos). 